\title{
Performance assessment of bifacial c-Si PV modules through device simulations and outdoor measurements
}

\author{
Th. Katsaounis ${ }^{* 1,3,4}$, K. Kotsovos ${ }^{\dagger 2}$, I. Gereige ${ }^{2}$, A. Basaheeh $^{2}$, M. Abdullah ${ }^{2}$, A. \\ Khayat $^{2}$, E. Al-Habshi ${ }^{2}$, A. Al-Saggaf ${ }^{2}$, and A.E. Tzavaras ${ }^{1}$ \\ ${ }^{1}$ Computer Electrical and Mathematical Science \& Engineering (CEMSE), KAUST, \\ Thuwal, Saudi Arabia \\ ${ }^{2}$ Renewable Energy, Carbon Management Division, Saudi Aramco, Thuwal, Saudi \\ Arabia \\ ${ }^{3}$ IACM, FORTH, Heraklion, Greece \\ ${ }^{4}$ Dept. of Math. \& Applied Mathematics, Univ. of Crete, Heraklion, Greece
}

\begin{abstract}
Bifacial solar cells are receiving increased attention in the PV market due to their higher energy yield compared to conventional monofacial modules thanks to additional light conversion through their back surface. This additional rear side energy gain creates a potential for significant reduction of the overall levelized cost of energy (LCOE). Despite this fact, wide deployment of bifacial PV modules is very limited because of the high unpredictability of their power output due to various factors such as ground reflectance, module elevation angle, orientation and tilt angle. Due to this complexity, modelling of bifacial modules and systems is currently not developed at the same level of maturity as monofacial ones, where established commercial tools have been developed for PV system designers. In this regard, a customized 2D device model has been developed to simulate bifacial PV structures based on the numerical solution of the transport equations by the finite element method. The model was used to simulate actual PV performance and energy yield based on measured outdoor environmental parameters including solar radiation spectrum and temperature. Bifacial device output was also compared with a monofacial one based on the industrial standard Al-BSF structure. Simulated results were also compared and validated with outdoor experimental data based on IV measurements of monofacial and bifacial modules installed at various tilt angles at a location near the Western coast of Saudi Arabia.
\end{abstract}

Keywords : customized 2D solar cell simulator, bifacial PV device, local climate conditions, hazy days favour bifacial devices

\section{Introduction}

Bifacial PV modules are continuously increasing their worldwide PV market share since they provide increased energy conversion compared to conventional monofacial devices due to their capability to absorb additional light through the back surface [1], [2], [3]. This fact provides a strong potential for bifacial solar modules to reduce the levelized cost of energy (LCOE) of PV generated electricity [4]. Therefore, large scale bifacial PV installations can potentially reach impressively low LCOE as already demonstrated by the worlds lowest bid for the Sakaka solar power project in Saudi Arabia [5]. Although bifacial PV structures were investigated since the 1960s [6], [7], their manufacturing process was too complicated for mass production at that time. Recent advances in industrial processes, however, have been implemented to reduce the cost of bifacial PV modules and various companies have introduced such products in their manufacturing lines [8], [9], [10], [11], therefore their market share is predicted to increase in the near

\footnotetext{
*theodoros.katsaounis@kaust.edu.sa(Corresponding author)

${ }^{\dagger}$ konstantinos.kotsovos@aramco.com
} 
future [12]. In addition, PV industry is shifting to high efficiency solar cell structures, like the passivated emitter and rear cell with local passivated contacts (PERC) [13], the n-Pasha (passivated on all sides $\mathrm{H}$ pattern), designed by ECN [14] and commercialized by Yingli [15], and the heterojunction PV structure originally developed by Panasonic [16], an already common technology choice for many PV manufacturers [17]. All these structures can be easily manufactured in bifacial configuration, while offering improved conversion efficiencies compared to the industrial standard Al-BSF (aluminium back surface field).

Bifacial PV modules are not widely deployed in PV system installations, however, because the evaluation of their field performance is challenging due to the variable illumination conditions on the back surface, which depend on different parameters, such as the percentage of diffuse radiation in the solar spectrum, ground reflectance, module elevation, orientation and tilt angle [1], [18]. The combinations of all these parameters complicates bifacial PV energy yield calculations and system design, thus negatively affecting the bankability of this technology. This is not the case for the standard monofacial PV's, where their performance and energy yield simulation can be easily implemented in commercially available PV software [19], [20], [21], [22]. In addition, currently available PV system design software typically use 1D circuit models for solar cell device simulations, which can be quite detailed, however they do not solve the solar cell transport equations, due to the increased computational load that is required.

In this regard, the development of a simulation software, which solves the carrier transport equations that could take into account various effects such as: the different illumination conditions on both surfaces, actual solar spectrum variations, operating temperature, various solar cell device structures and material parameters to accurately evaluate the PV module electrical output, is beneficial. This fully customized model will enable PV developers to calculate with high accuracy the optimal system design based on various available solar cell technologies, local weather parameters and PV system configuration.

Based on the above, the purpose of this study is the application of a customized model based on the solution of the solar cell device transport equations in 2D, specifically designed for bifacial solar cells similar to PERC to simulate outdoor field performance and energy yield of such devices and comparing their output gain with monofacial structures. The simulations are performed using locally measured outdoor environmental parameters including solar radiation spectrum and temperature, while calculated data are compared and validated with actual measurements on commercial monofacial and bifacial PV modules. The measurements are performed for various PV module tilt angles. The formulation of the model is based on the one developed in [23], which is extended to take into account temperature dependence of device parameters. The model with its accompanying assumptions and fitted experimental parameters is analyzed in section 2, while the experimental outdoor measurement setup is described in section 3. Simulation results and comparison with experimental data obtained from the outdoor measuring setup are presented in section 4 and an extended discussion on these results is provided in section 5. Finally, section 6 discusses the main conclusions and future perspectives of this work.

\section{The mathematical model}

In the previous study [23], the authors introduced a new mathematical model for PERC p-type c-Si solar cell, see Figure 1(left), based on the assumptions that there are no transient phenomena and that the cell operates in the low injection regime. In this regime the classical drift-diffusion model can be simplified considerably since diffusion dominates current transport. After an appropriate change of variables the new dimensionless system reads as follows

$$
\begin{aligned}
-\Delta \eta+\eta & =g_{n}(z), & & (x, z) \in[0, L] \times[0, w], \\
-\Delta u+\eta & =g_{n}(z), & & (x, z) \in[0, L] \times[0, w],
\end{aligned}
$$

where $u=\frac{V}{V_{C}}$ is a scaled voltage drop and $\eta=\frac{n}{N_{A}}$ is a scaled electron concentration, while $L$ is the pitch(length) of the cell and $w$ its width. The source $g_{n}(z)=\frac{L_{n}^{2}}{N_{A} D_{n}} G(z)$ describes a scaled generation rate $G(z)$ with $L_{n}$ being the diffusion length, $N_{A}$ is the hole doping density and $D_{n}, D_{p}$ are the electron and hole diffusivity constants with $\mu_{n}, \mu_{p}$ being the corresponding mobilities. The model is augmented with the following set of linear and nonlinear boundary conditions, [24] :

- Vertical sides: $x=0, L, z \in(0, w)$,

$$
\nabla \eta \cdot \zeta=0, \quad \nabla u \cdot \zeta=0 .
$$



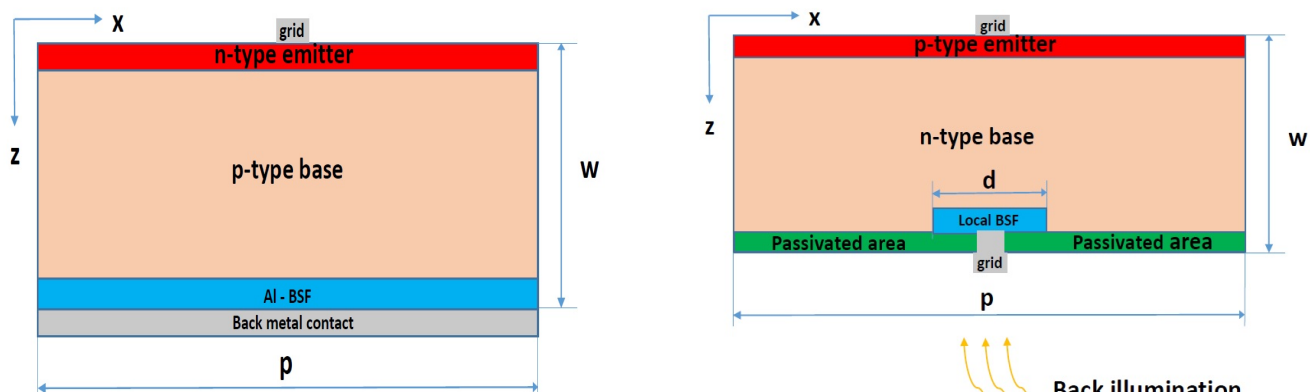

Back illumination

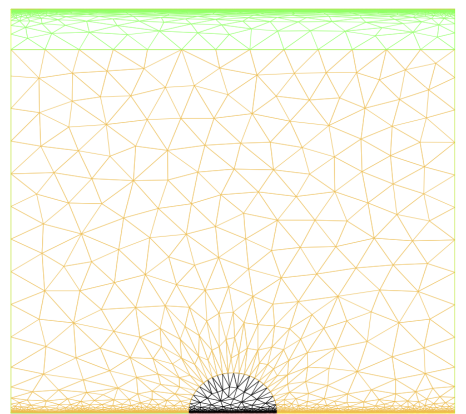

Figure 1: Geometry of a monofacial(top-left), bifacial solar device (top-right) and a representative triangulation (bottom)

- Top side: $z=0, x \in(0, L)$,

$$
\nu_{A}^{2} \eta=\exp \left(\frac{V_{C}}{V_{T}}\left(V_{b}+u\right)\right)-1, \quad \nabla u \cdot \zeta=\nu_{A}^{2} j_{0}\left(1-\exp \left(-\frac{V_{C}}{V_{T}}\left(V_{b}+u\right)\right)\right) .
$$

- Bottom side : $z=w, x \in(0, L)$,

$$
\begin{aligned}
& \nabla \eta \cdot \zeta=-s_{n} \eta, \\
\text { outside contact }: & \nabla u \cdot \zeta=-s_{n} \eta, \\
\text { inside contact }: & u=0,
\end{aligned}
$$

where $\zeta$ is the outward normal to the side, $V_{T}$ is the thermal voltage and $V_{C}=\frac{D_{n}-D_{p}}{\mu_{p}}$. The recombination velocity $S$ is : $S=s_{1}$ outside the contact and $S=s_{2}$ inside the contact. Further, $n_{i}$ denotes the intrinsic carrier concentration, $J_{0}$ the saturation current density and $V_{\text {bias }}$ is the external applied voltage with $V_{b}=\frac{V_{b i a s}}{V_{C}}, \nu_{A}=\frac{n_{i}}{N_{A}}, j_{0}=J_{0} \frac{L_{n}}{q D_{p} N_{A}} \frac{V_{T}}{V_{C}}$ and $s_{n}=S \frac{L_{n}}{D_{n}}$.

Remark 2.1 The corresponding mathematical model for an n-type solar cell is completely analogous to (1)-(4), where the variable $\eta$ is replaced by $\tau=\frac{p}{N_{D}}$ with $p$ denoting the hole concentration.

\subsection{Solar cell simulator: KASCS}

System (1)-(4) is solved numerically using the finite element method. An implicit - explicit variant of Newton's method is used to linearize the system and solve each equation separately thus reducing the computational cost considerably. Mesh adaptivity, see Figure 1(bottom), is used to resolve the Dirac-like behaviour of the incident light on the cell surface as well as to capture the steep gradients of the solution around the back contact. The solver was tested and compared with various well known open source solar cell simulators. Further details can be found in [23]. 
Various features are included in the solar cell simulator concerning shading, reflection and temperature effects. In particular,

- the cell surface texturing is assumed to be of pyramidical shape with angle of $45^{\circ}$;

- the effect on the incident solar irradiance of the geographical location and the tilt angle of the PV module, were also considered

- the shading of metallic grid and busbar was included

- the reflection of the incident light from the solar cell surface and the glass of the module was taken into account

- the dependance on temperature of various parameters of the problem: $n_{i}, \mu_{n}, \mu_{p}, J_{0}$ was also considered.

All the numerical results reported were obtained using linear finite elements. The computational domain was covered by a triangulation, which initially was adapted according to the variation of $g_{n}(z)$ and subsequently according to the solution iterates, see Figure 1(bottom). Part of the code was developed using the FreeFem ++ finite element computational framework [25]. The iterative scheme with mesh adaptivity converges in few iterations $1 \leq \ell_{m} \leq 4$ with a tolerance of $10^{-12}$ between two successive iterates. Further, the computational time to obtain an IV-curve consisting on the average of 120 points varied from $10-30 \mathrm{~min}$. We remark that our solver KASCS uses and adaptive algorithm to choose the voltage step in the calculation of an IV-curve. The numerous simulations were performed on the CRAY XC40(Shaheen) of the Supercomputing Laboratory at King Abdullah University of Science \& Technology (KAUST) in Thuwal, Saudi Arabia.

\section{$3 \quad$ Experimental setup}

The outdoor experimental system is installed at KAUST in Thuwal, western region of Saudi Arabia at the New Energy Oasis (NEO) test field near the Red Sea coast (22.30 N, 39.10 E). The system consists of the following components:

- Two commercial PV modules, a monofacial and a bifacial one, with ground mounting system

- IV measuring system with radiation sensors

- Solar resource measurement station

The system components are analyzed in the following subsections.

\subsection{PV modules and mounting systems}

The modules selected for this study consist of a monofacial polycrystalline Si PV module and a bifacial monocrystalline $\mathrm{Si}$, which are chosen to have similar electrical characteristics based on their manufacturer datasheets as shown on Table 1 . The modules were installed in a standard $\mathrm{Al}$ profile mounting system with south facing orientation, where the system was designed to support various tilt angles. Testing was performed at 25, 45 degrees tilt angles, with $20 \mathrm{~cm}$ module elevation. The ground is paved with grey coloured gravel. A picture of the installed modules at 25 degrees tilt is illustrated on Figure 2, where on the left is the location of the monofacial polycrystalline module, while on the right is the bifacial one. The modules were connected to an IV measuring system with multiple inputs in order to monitor the electrical characteristics of each one separately, as described in the next section.

\subsection{Measuring system}

The electrical output of each module was measured individually through an IV tracer system with multiple inputs. The system was designed and supplied by IMT Solar [26], using a high resolution IV curve analyzer, with a capacitive load and high speed data acquisition system capable of measuring a wide range of PV modules. The system is combined with a multiplexer to allow simultaneous measurements of multiple connected modules using 4 wire connections for IV measurements. Finally the setup includes an 
Table 1: PV module specifications based on manufacturer's datasheets

\begin{tabular}{||l|l|l||}
\hline PV module characteristics & Module 1(Monofacial) & Module 2(Bifacial) \\
\hline \hline Technology & Polycrystalline & Monocrystalline \\
\hline Dimensions $(\mathrm{cm})$ & $166.5 \times 99.1$ & $165.6 \times 98.4$ \\
\hline Module type & Glass/backsheet, framed & Double Glass, frameless \\
\hline Number of cells & 60 & 60 \\
\hline Estimated Cell area $\left(\mathrm{cm}^{2}\right)$ & 243.36 & 241.36 \\
\hline Maximum Power $(\mathrm{W})$ & 240 & 245 \\
\hline Maximum Current $(\mathrm{A})$ & 8.17 & 8.14 \\
\hline Maximum Voltage $(\mathrm{V})$ & 29.7 & 30.1 \\
\hline Short Circuit Current $(\mathrm{A})$ & 8.75 & 8.76 \\
\hline Open Circuit Voltage $(\mathrm{V})$ & 36.8 & 38.5 \\
\hline Fill Factor $(\%)$ & 75.36 & 72.65 \\
\hline Module Efficiency $(\%)$ & 14.5 & 15.1 \\
\hline NOCT $\left({ }^{\circ} \mathrm{C}\right)$ & 45.7 & 48.9 \\
\hline Temperature coefficient of $P_{M P P}\left(\% /{ }^{\circ} \mathrm{C}\right)$ & -0.40 & -0.465 \\
\hline Temperature coefficient of $V_{o c}\left(\% /{ }^{\circ} \mathrm{C}\right)$ & -0.27 & -0.332 \\
\hline Temperature coefficient of $I_{s c}\left(\% /{ }^{\circ} \mathrm{C}\right)$ & 0.024 & 0.096 \\
\hline
\end{tabular}

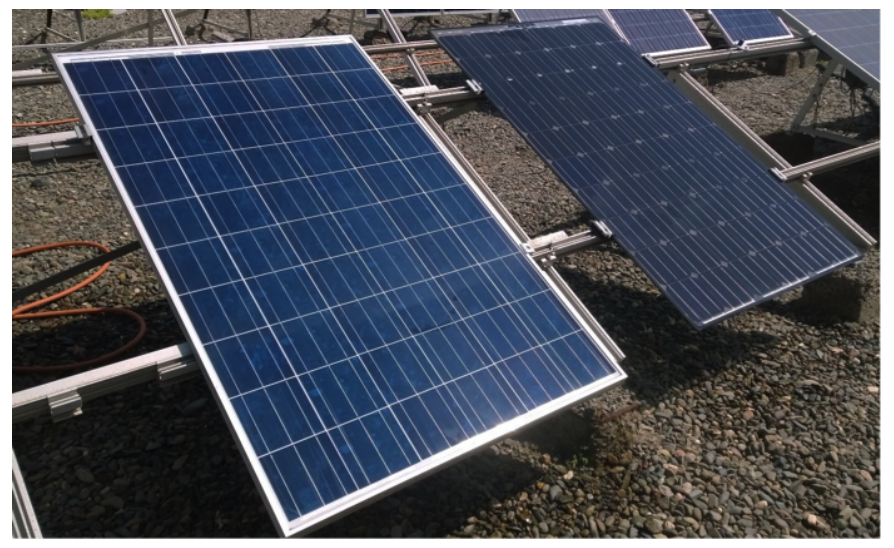

Figure 2: Installed PV modules at 25 degrees tilt. On the left is the location of the monofacial polycrystalline module, while on the right is the bifacial one.

integrated industrial PC with Labview based data acquisition software to store the measured curves and sensor inputs (temperature and radiation). The whole system is integrated in a ventilated cabinet with a stainless steel hood to protect it from direct sunlight. Solar intensity is measured using two calibrated Si based irradiation sensors, connected at the front and back side of the module at the same inclination angle. The system is illustrated on Figure 3, while its specifications are listed on Table 2. 


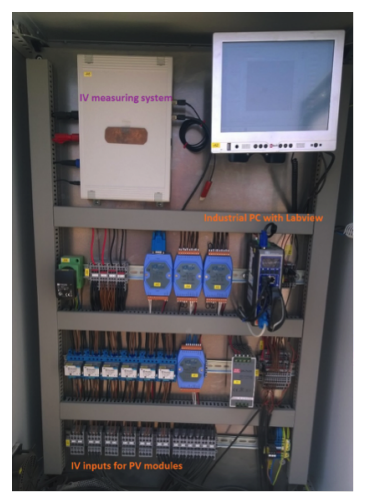

Table 2: IV tracer system technical specifications

\begin{tabular}{||l|l||}
\hline IV tracer system technical data & \\
\hline \hline Data acquisition system & 16 bit \\
\hline Voltage Range $(\mathrm{V})$ & $50-200$ \\
\hline Current Range $(\mathrm{A})$ & $4-32$ \\
\hline Irradiance Range $\left(\mathrm{W} / \mathrm{m}^{2}\right)$ & 1300 \\
\hline Temperature Range $(\mathrm{C})$ & $0-100$ \\
\hline Measuring time for IV curve (ms) & $2-500$ \\
\hline Maximum points per IV curve & 4000 \\
\hline Number of PV module inputs & 6 \\
\hline Basic accuracy (\% full scale reading) & \pm 0.2 \\
\hline
\end{tabular}

Figure 3: IV tracer system with multiple inputs for measuring the output of the monofacial and bifacial Basic accuracy (\% full scale reading) modules.

\subsection{Solar resource measurement station}

The solar resource measurement station is installed in the same outdoor field, near the site where the PV module measurement setup is located. The setup as shown on Figure 4 includes four sensors to perform precise measurements of the three solar radiation components: Spectral Global Horizontal Irradiance (sGHI), Global Horizontal Irradiance (GHI), Direct Normal Irradiance (DNI), Diffuse Horizontal Irradiance (DHI) and the global spectral distribution (s-GHI). It also includes a sky camera to take hemispheric pictures of the sky. The system is designed and installed by TUV Rheinland who has installed a similar system for measuring solar and weather resources in KAUST as a part of the national research project PVKLIMA [27], while its sensors and cameras are supplied by EKO Instruments [28]. The system includes a standard sun-position sensor and GPS receiver. To measure the diffuse component of the solar radiation, a shading disk assembly is mounted on one arm of the tracker. The main specifications of the sensors are summarized on Table 3. The data acquisition system consists of a data-logger (Campbell

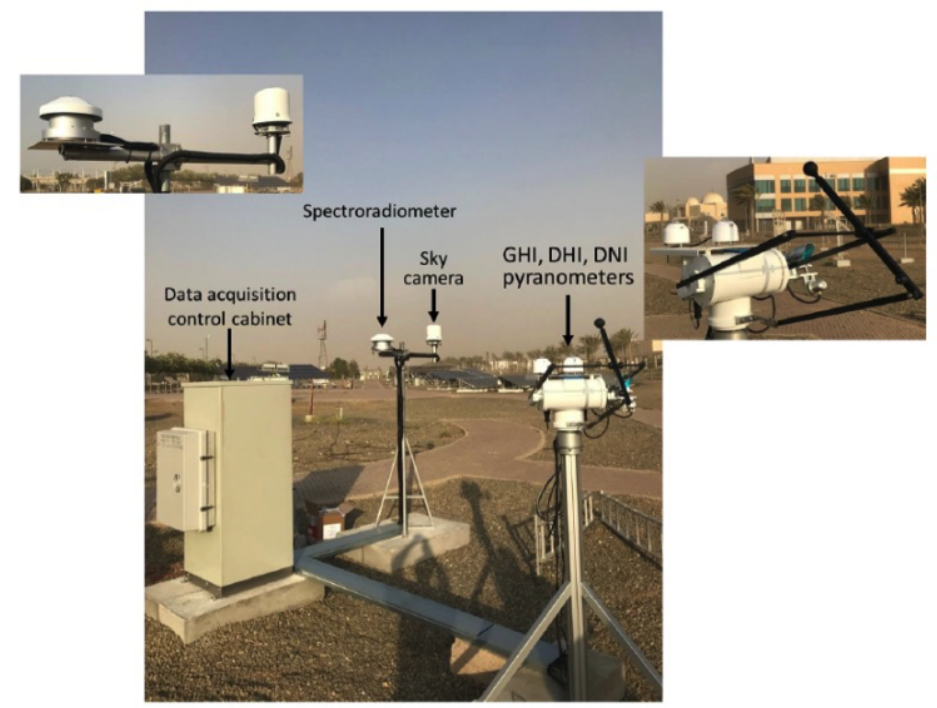

Figure 4: Solar resource monitoring station installed at KAUST NEO PV test site.

Scientific CR1000 [29]) to record sensor data over time. The solar data and sky images are also collected at specified time intervals. The electronic components are housed in a cooled cabinet to maximize their lifetime in hot-humid outdoor conditions. The system is equipped with a UPS to keep the measurement running for 2 hours in case of a power shortage. 
Table 3: Sensor specifications of the solar resource station

\begin{tabular}{|c|c|c|c|c|}
\hline Specifications & $\begin{array}{l}\text { Spectroradiome- } \\
\text { ter }\end{array}$ & $\begin{array}{l}\text { Pyranome- } \\
\text { ters }\end{array}$ & $\begin{array}{l}\text { Pyrheliome- } \\
\text { ter }\end{array}$ & Sky camera \\
\hline $\begin{array}{l}\text { Measurement } \\
\text { type }\end{array}$ & spectrum-GHI & $\begin{array}{l}\text { GHI/DHI } \\
\text { DNI }\end{array}$ & $\begin{array}{l}\text { Hemispheri- } \\
\text { cal sky } \\
\text { pictures }\end{array}$ & \\
\hline Model & EKO MS-711 & EKO MS-80 & EKO MS-56 & EKO ASI-16 \\
\hline $\begin{array}{l}\text { Wavelength } \\
\text { Range (nm) }\end{array}$ & $300-1100$ & $\begin{array}{l}285-3000 \\
\mathrm{~nm}\end{array}$ & $200-4000$ & $\mathrm{~N} / \mathrm{A}$ \\
\hline $\begin{array}{l}\text { Operating } \\
\text { temperature } \\
\text { range }\left({ }^{\circ} \mathrm{C}\right)\end{array}$ & -10 to 50 & -40 to 80 & -40 to 80 & -35 to 55 \\
\hline Accuracy & $\begin{array}{l} \pm 0.2 n m \\
\text { (wavelength) }\end{array}$ & $\begin{array}{l} \pm 0.5 \% \\
\text { (stability } \\
\text { change/ } \\
\text { 5-years) }\end{array}$ & $\begin{array}{l}<0.5 \% \\
\text { (stability } \\
\text { change/ } \\
5 \text {-years) }\end{array}$ & $\mathrm{N} / \mathrm{A}$ \\
\hline $\begin{array}{l}\text { Other } \\
\text { features }\end{array}$ & $\begin{array}{l}\text { FOV } 1800, \\
\text { Integrated temp. } \\
\text { control }\left(25^{\circ} \mathrm{C}\right)\end{array}$ & $\begin{array}{l}\text { ISO } 960 \\
\text { Secondary } \\
\text { Standard }\end{array}$ & $\begin{array}{l}\text { ISO } 960 \\
\text { First Class }\end{array}$ & $\begin{array}{l}5 \mathrm{MP} \text { resolution, } \\
\text { FOV 1800, } \\
\text { Integrated temp. } \\
\text { control }\end{array}$ \\
\hline
\end{tabular}

\subsection{Data acquisition - Measurements}

The experiments on both PV modules were conducted in two different time periods each corresponding to a different tilt angle as it's shown in Table 4. During these periods we have recorded on a daily

Table 4: Time periods and PV module tilt angles.

\begin{tabular}{||c|c||}
\hline Time Period & Tilt angle \\
\hline $28 / 03 / 2018-06 / 04 / 2018$ & 25 \\
\hline $23 / 04 / 2018-05 / 05 / 2018$ & 45 \\
\hline
\end{tabular}

basis and at 5 minutes interval the direct and reflected solar irradiance, solar spectrum and ambient temperature. The IV curves of both PV modules were also measured with the same frequency providing us with operational characteristic quantities of the modules such as $V_{o c}$ and $I_{s c}$. The material used for PV module encapsulation is considered as EVA-type, where its reflection coefficient was measured using an encapsulated glass - EVA sample with an Agilent Cary 7000 universal measurement spectrophotometer, using the integrating sphere technique, is shown in Figure 5. All these measurements are used to setup our solar cell simulator.

\section{Simulations - Experimental results}

\subsection{Simulation characteristics and parameters}

The simulated bifacial PERC type solar cell structure is illustrated in Figure 1(left), where the emitter is covering the front surface, while the back surface is passivated and the contacts are stripe-shaped due the considered 2D geometry. The cell base substrate is n-type with uniform doping density $N_{D}=10^{16} \mathrm{~cm}^{-3}$, while carrier mobility values and intrinsic concentration are taken from [30]. We also assume an ideal thin emitter covering the entire front surface, where photogeneration is occurring in the base only, while the base emitter saturation current is $J_{0}=10^{-13} \mathrm{~A} / \mathrm{cm}^{2}$. The recombination velocity at the back passivated area is considered $S_{1}=10 \mathrm{~cm} / \mathrm{s}$, which is typical of silicon oxide or nitride passivation layers [31], while at the back contacts is calculated by the following expression: $S_{2}=\frac{J_{0 C} N_{D}}{q n_{i}^{2}}$, where $J_{0 C}$ is the recombination current at the back contact which is assumed as $J_{0 C}=4 \cdot 10^{-12} \mathrm{~A} / \mathrm{cm}^{2}$. This surface recombination value 


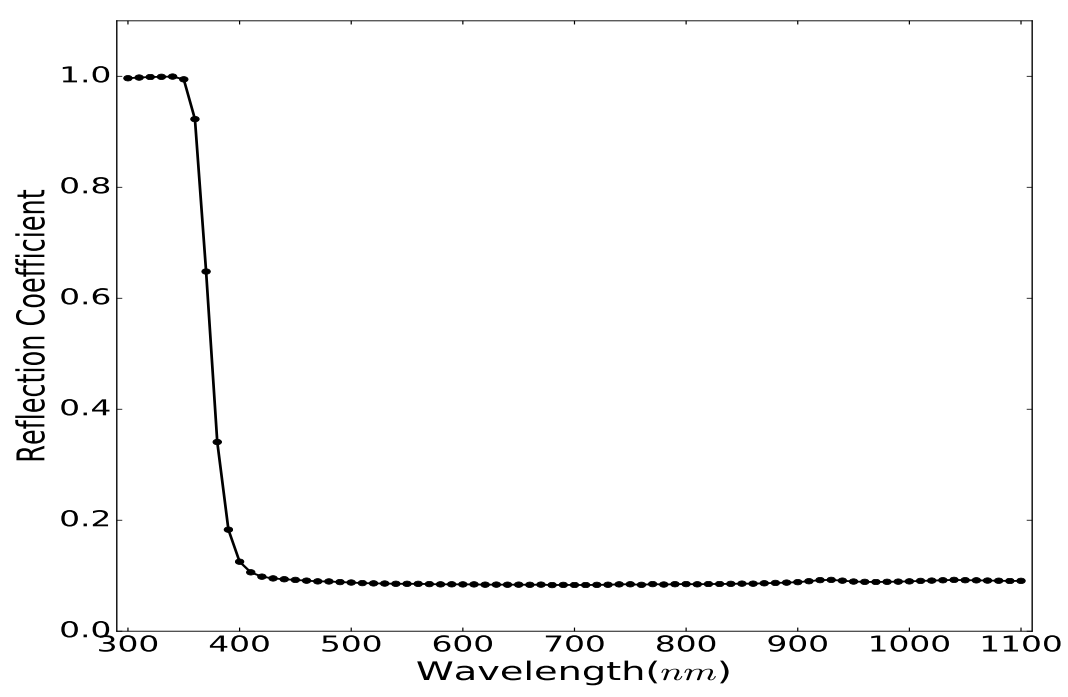

Figure 5: Reflection coefficient of EVA-type glass

corresponds to a recombination velocity within the range observed for Al-BSF laser fired contacts used in PERC solar cells [32]. The simulated monofacial PERC solar cell is p-type Al-BSF structure with uniform base doping density $N_{A}=10^{16} \mathrm{~cm}^{-3}$, where carrier mobilities and intrinsic concentration taken from [30]. The base emitter saturation current and velocity $S_{2}$ are taken as in the bifacial cell, while $J_{0 C}=10^{-12} \mathrm{~A} / \mathrm{cm}^{2}$. In both solar cells the metallic grid fingers have width $100 \mu \mathrm{m}$ which is assumed to be in the centre of the cell, while the busbar reduces the incident light by $2.3 \%$. In the simulations we assume that each cell has length $p=1200 \mu \mathrm{m}$ and width $w=180 \mu \mathrm{m}$, see Figure 1 (left, right). The back contact covers the whole back surface of the cell in the monofacial module while in the bifacial one it is at $10 \%$ of its length.

The effect of the location and tilt angle of module on the incident solar irradiance is also accounted for. For the aforementioned time periods the corresponding coefficient $C_{S}$, which scales the solar irradiance, was found to vary considerably mainly due to the tilt angle: $C_{S} \in[1.05915,0.994513]$ for $25^{\circ}$ tilt angle, $C_{S} \in[0.832718,0.783781]$ for $45^{\circ}$ tilt angle.

The solar cells themselves also reflect light and this is also considered in our simulations. The corresponding reflection coefficients for the monofacial and bifacial solar cells were obtained from [30].

\subsection{Temperature effects}

One of the most important factors affecting solar cell operation is temperature. In the literature, most studies assume that the cell operates under nominal (STC) conditions $\left(25^{\circ} C\right)$ which is not the case in reality. In many areas of the Middle East region the ambient temperature can rise several degrees above nominal conditions and module temperature can reach as high as $60^{\circ} \mathrm{C}$ or more. Temperature affects several material parameters, which can considerably reduce PV module efficiency. These temperature effects are incorporated in our solar cell simulator.

In the literature there are several models for estimating the PV module operating temperature. A set of models use electrical characteristics of the module, e.g. $V_{o c}$ and/or $I_{s c}$ which under operating conditions they are not available. Another group of models use parameters which, in general, are available a priori, such as air temperature $\left(T_{a i r}\right)$, solar irradiance $\left(G_{i r r}\right)$, wind velocity $\left(v_{w}\right)$ and efficiency of the module $\left(\eta_{\text {ref }}\right)$. In this study we focus on such type of models, see [33], [34], [35], [36], [37] respectively, where all the involved quantities are provided a priori either by the manufacturer, see Table 1, or by our 
measurements:

$$
\begin{aligned}
T_{c}^{t} & =T_{a i r}+\frac{G_{i r r}}{800}\left(T_{N O C T}-20\right)\left(1-\eta_{m}\right)\left(\frac{9.5}{5.7+3.8 v_{w}}\right), \quad\left({ }^{o} C\right) \\
T_{c}^{S} & =T_{a i r}+0.0138 G_{i r r}\left(1+0.031 T_{a i r}\right)\left(1-0.042 v_{w}\right)\left(1-1.053 \eta_{m}\right), \\
T_{c}^{C} & =0.943 T_{a i r}+0.028 G_{i r r}-1.528 v_{w}+4.3, \quad\left({ }^{o} C\right) \\
T_{c}^{L} & =30.006+0.0175\left(G_{i r r}-300\right)+1.14\left(T_{a i r}-25\right), \quad\left({ }^{o} C\right) \\
T_{c}^{K} & =T_{a i r}+G_{i r r} e^{-3.473-0.0594 v_{w}}, \quad\left({ }^{o} C\right) .
\end{aligned}
$$

To assess the effectivity of (5)-(9) we setup an experiment where the temperature of both modules was measured for a period of six days in July 2018 during sunlight hours and sampled every five minutes. The wind values were obtained from a TMY of [38] for the location of KAUST university. The behaviour of the five models is shown in Figure 6 along with the measurements $T^{m}$ (red line). It should be noted that the measured module temperature do not represent actual PV cell operating temperature because the sensors are attached to the insulated (backsheet or glass) back module surface. This measurement deviation also depends on the type of the sensor used, its attachment method, as well as weather conditions such as irradiance and wind speed [39]. The root mean square(RMS)-differences for each model is also depicted in the figure. All models agree very well with measurements during morning and afternoon hours of the day, while substantial differences are observed around noon hours, where temperature reach peak values. The curve representing the measurements lie in between the predictions of the models, however, it is apparent that there is no clear advantage of using any particular model among (5)-(9). Based on
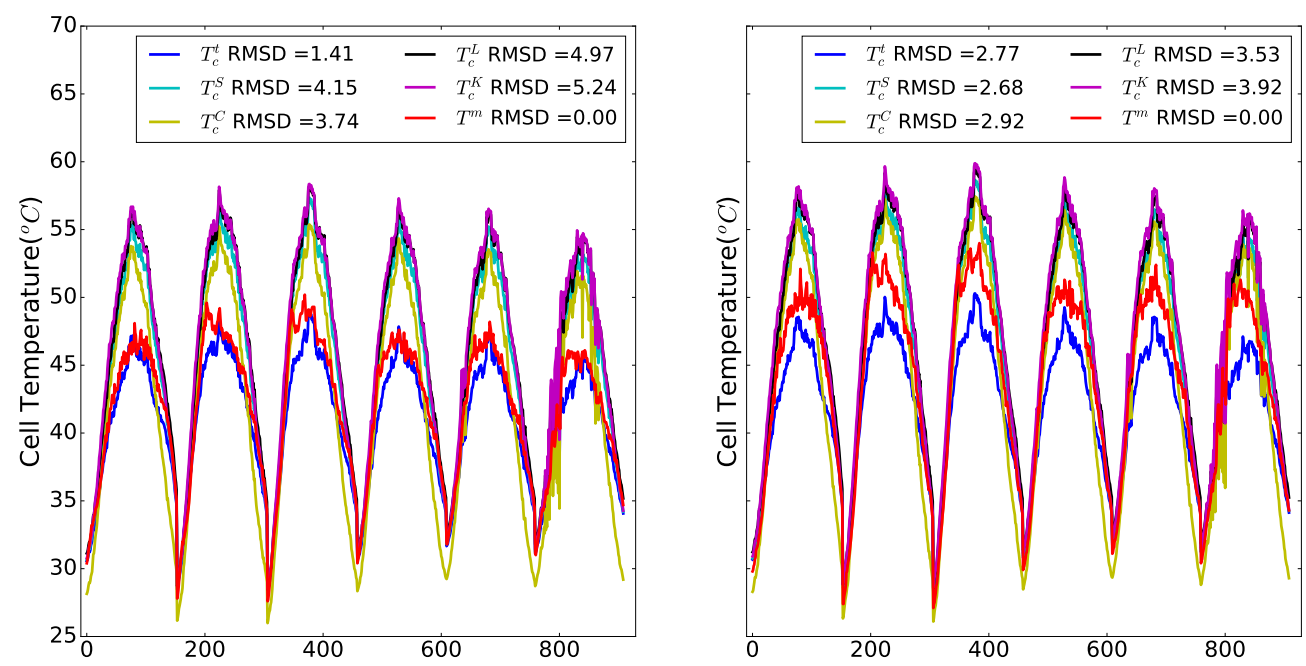

Figure 6: PV module temperature models performance: Monofacial(left), Bifacial(right).

this observation we proceed by taking a linear combination of all aforementioned models to estimate the module temperature :

$$
T_{c}^{L S}=w_{t} T_{C}^{t}+w_{S} T_{c}^{S}+w_{C} T_{c}^{C}+w_{L} T_{c}^{L}+w_{K} T_{c}^{K}
$$

where $w_{t}, w_{S}, w_{C}, w_{L}, w_{K}$ are real numbers to be determined by linear least square fitting to the measurements. At this point we can use the whole or part of the dataset of measurements to train the weights. In Table 5 the corresponding RMSD's are shown using from one up to six days of measurements. It was observed that essentially the RMSD value remains unchanged using only half of the dataset with less than of $1^{\circ} \mathrm{C}$ of difference. The weights obtained using the whole set of measurements are shown in Table 6 . These values depend on the underlying module technology but they are independent of the tilt angle and will be used in the sequel to estimate the PV modules operating temperatures for both periods 
Table 5: Training days and corresponding RMSD's

\begin{tabular}{||l|c|c|c|c|c|c||}
\hline Days & 1 & 2 & 3 & 4 & 5 & 6 \\
\hline Monofacial & 1.145 & 0.804 & 0.762 & 0.748 & 0.739 & 0.738 \\
\hline Bifacial & 1.309 & 1.023 & 0.985 & 0.958 & 0.942 & 0.936 \\
\hline \hline
\end{tabular}
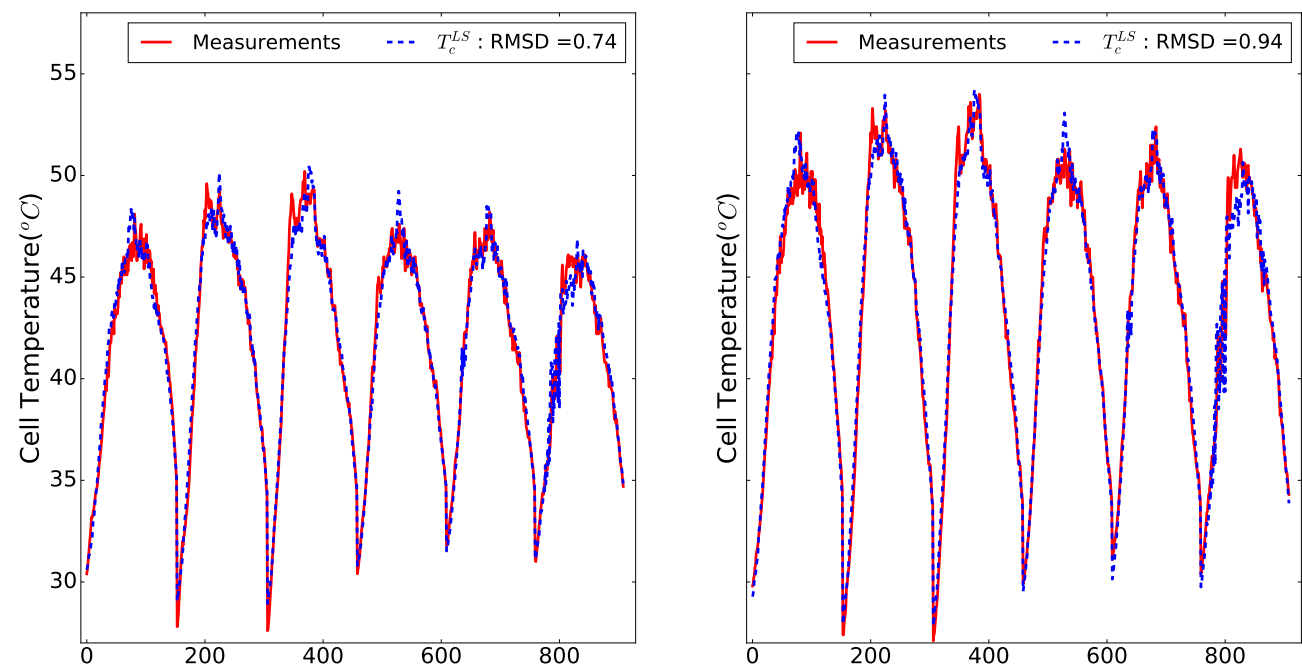

Figure 7: Least squares approximation $T_{c}^{L S}$ : Monofacial(left), Bifacial(right).

Table 6: Weights of $T_{c}^{L S}$ obtained from the whole dataset

\begin{tabular}{||l|c|c|c|c|c||}
\hline Weights & $w_{t}$ & $w_{S}$ & $w_{C}$ & $w_{L}$ & $w_{K}$ \\
\hline Monofacial & 0.68063 & 2.05398 & -0.77271 & -2.01659 & 1.01839 \\
\hline Bifacial & -0.00491 & 2.06415 & -1.10514 & -2.22521 & 2.15693 \\
\hline
\end{tabular}

of testing. The effectiveness of this approach is demonstrated further in Figure 7 where the measured values of module temperature and their estimation by $T_{c}^{L S}$ are shown. According to the estimation of PV module operating temperature provided by $T_{c}^{L S}$ we modify several material parameters affected by the temperature. The main focus was on parameters with significant contribution to PV module operation: a) silicon light absorption coefficient $(\alpha(\lambda))$, b) intrinsic carrier concentration $\left(n_{i}\right)$, c) carrier mobilities $\left.\mu_{n}, \mu_{p}, \mathrm{~d}\right)$ saturation current density $J_{0}, J_{0 C}$, e) electron lifetime $\tau_{n}$.

The temperature effects on the light absorption coefficient are calculated using an exponential law proposed in the study by M.A. Green [40]. To account for the changes on intrinsic carrier concentration and carrier mobilities, the study of PVLighthouse [30] was considered. In particular for temperatures ranging from $280^{\circ} \mathrm{K}$ to $370^{\circ} \mathrm{K}$ with step of $10^{\circ} \mathrm{K}$ we obtain the corresponding values of carrier intrinsic concentration and mobilities. For any value of the temperature $T_{c}^{L S}$ in this range the required value is computed by linear interpolation. The other two quantities, $J_{0}, \tau_{n}$, are a little bit more involved. For saturation current we follow the approach suggested in [41] which expresses $J_{0}$ in terms of energy bandgap and a nonlinear temperature term. Concerning the electron lifetime $\tau_{n}$ the model proposed in [42] was used.

Remark 4.1 This is the first exploratory step to study the effect of temperature in solar cell operation focused only on the variation of certain material parameters affected by thermal changes and their effect in the cell performance. A more comprehensive approach to evaluate the temperature effects in solar cells would have to include also an energy equation in the mathematical model. This goes beyond the current scope and will be the subject of future work. 


\subsection{Resistance effects}

The mathematical model and the solar simulator don't include any external resistance effects related to PV module and system design, which are influenced by cell interconnection in series or parallel, cabling losses as well as current mismatches between different cells. Commonly in PV modules series and shunt resistances due to these factors are important sources of power output loss. Our goal is to estimate these resistances and account for their effect by correcting-modifying the simulated IV-curves on a posteriori way. In the literature several ways were proposed to estimate these resistances see e.g. [43] and the references therein. In this work, a different approach based on the experimental data collected was followed. The effect of both series and shunt resistances is given by the well known formula

$$
I=I_{s c}-I_{0}\left(\exp \left(\frac{V+I R_{s}}{m V_{T}}\right)-1\right)-\frac{V+I R_{s}}{R_{s h}},
$$

where $V_{T}=\frac{\kappa T}{q}$ is thermal voltage, while the saturation current $I_{0}$, resistances $R_{s}, R_{s h}$ and ideality factor $m$ are unknown quantities to be determined. To estimate these parameters we use the available measurements and nonlinear least squares approximation. We proceed then to correct the simulated IVcurve and compute its characteristic quantities by solving the equation (11). The procedure we follow is now described in detail.

The estimation of the parameters will be done in a gradual way, thus at every step of the process one parameter will be determined and take a definite value. First we take, without loss of generality, $m=1$. The value of $I_{0}$ is computed by the data of the simulated IV-curve using the following well known formula, while the temperature is estimated following the process described in the previous section,

$$
V_{o c}=m V_{T} \log \left(\frac{I_{s c}}{I_{0}}+1\right) \Longrightarrow I_{0}=I_{s c}\left(e^{\frac{V_{o c}}{m V_{T}}}-1\right)^{-1}
$$

To estimate the resistances $R_{s}, R_{s h}$, we perform first a nonlinear least square fitting to (11) for all experimental IV-curves with irradiance greater than $800 \mathrm{~W} / \mathrm{m}^{2}$. It was observed that the series resistance, with an average value $R_{s}^{a v g}=2.02$ and standard deviation $R_{s}^{s t d}=0.026$, remained the same for both monofacial and bifacial modules, tilt angles and its dependence on temperature and solar irradiance is negligible. A typical example of this behaviour of $R_{s}$ is shown in Figure 8. Motivated by the distribution
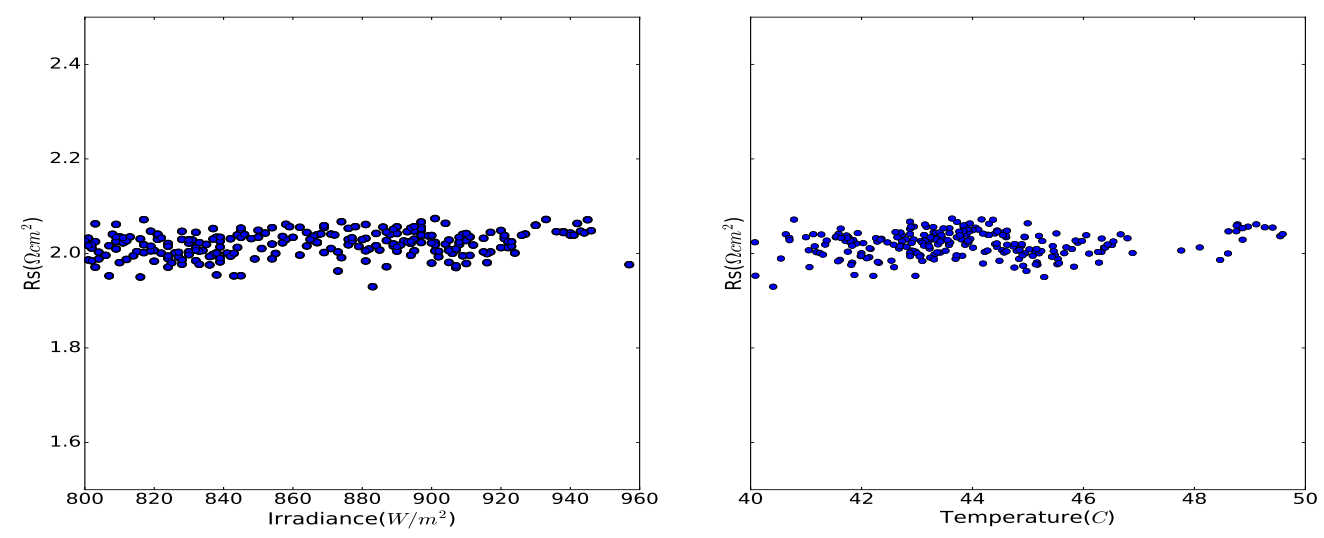

Figure 8: Distribution of series resistance $R_{s}$

of the values of $R_{s}$ we set $R_{s}=2$ in (11) and we perform another nonlinear least square fitting to estimate the shunt resistance $R_{s h}$. There is no clear dependence of $R_{s h}$ from the temperature, however $R_{s h}$ decreases linearly with respect to solar irradiance, [44]. Table 7 shows the coefficients of the corresponding linear least square fitting for each module and tilt angle. To recap, for a given simulated IV-curve its correction is obtained by taking $m=1, R_{s}=2, I_{0}$ from (12), $R_{s h}$ from Table 7 and solving (11). 
Table 7: Least square fitting of $R_{s h}$ with respect to solar irradiance $G_{i r r}$

\begin{tabular}{|l|l|}
\hline Monofacial, 25 & $R_{s h}=-0.759 G_{i r r}+1089$ \\
\hline Monofacial, 45 & $R_{s h}=-0.705 G_{i r r}+966$ \\
\hline Bifacial, 25 & $R_{s h}=-0.397 G_{i r r}+663$ \\
\hline Bifacial, $45^{\circ}$ & $R_{s h}=-0.494 G_{i r r}+787$ \\
\hline
\end{tabular}

\subsection{Daily yield output}

In this section we first compare various characteristic quantities of the PV modules obtained from the simulations with the corresponding ones from measurements. The time series over both time periods of maximum power $P_{w r}, V_{o c}, I_{s c}$ are shown in the following Figures 9, 10 for monofacial and bifacial device for the two tilt angles. The relative RMS-error of each variable is also included in the figures. The high oscillatory behaviour observed in power and current for both devices during the first period, Figures 9, 10 is not related to the tilt angle but it's due to the presence of a light sandstorm in the area. This type of phenomena are quite typical in the middle eastern countries resulting in substantial reduction of the direct solar irradiance, see also Figures 16, 17. During the second period with tilt angle $45^{\circ}$, no such phenomenon occurred, which is evident by the oscillations-free smooth daily variations of the relative quantities and also reflected on the corresponding RMSD values, see Table 8. It's also worth noticing the very close match of short circuit current between simulations and experimental values for both devices and tilt angles, which is a result of using exact spectral data to perform the simulations.

Table 8: RMSD values of module characteristic parameters

\begin{tabular}{|c|c|c||c|c|}
\hline & \multicolumn{2}{|c|}{ Period 1 (tilt angle $\left.25^{\circ}\right)$} & \multicolumn{2}{c|}{ Period 2 (tilt angle $\left.45^{\circ}\right)$} \\
\hline \hline & Monofacial & Bifacial & Monofacial & Bifacial \\
\hline$P_{w r}$ & 24.0822 & 25.9262 & 11.9460 & 13.4741 \\
\hline$V_{m p}$ & 0.0521 & 0.0617 & 0.0505 & 0.0570 \\
\hline$I_{m p}$ & 0.0032 & 0.0028 & 0.0014 & 0.0015 \\
\hline$V_{o c}$ & 0.0147 & 0.0058 & 0.0141 & 0.0064 \\
\hline$I_{s c}$ & 0.0030 & 0.0028 & 0.0017 & 0.0019 \\
\hline$F F$ & 0.0960 & 0.1180 & 0.0983 & 0.1115 \\
\hline
\end{tabular}

A parity plot between simulation results and experimental values, corresponding to figure 10 is shown in Figure 11. The parity line (graph bisector) is also added as reference, demonstrating the close agreement between the predictions of the mathematical model and the measurements. In Figures 12, 13 the daily yield output $(k w h / k w p)$ is shown for each tilt angle. In each figure the left graph is for the monofacial module while the right graph refers to the bifacial one. Both graphs show good agreement with the experimental curves following exactly the measured daily energy yield changes, thus validating our model. A third curve is also shown in each graph corresponding to the corrected-simulated IV-curve taking into account PV module series and shunt resistance following the correction process described in the previous section. The agreement of corrected daily yield output with the experimental data is remarkable thus validating the aforementioned correcting process. Table 9 shows the absolute and relative differences, measured in the discrete 2-norm of simulated and corrected daily yield output with respect to experimental data for the whole time period. The parity plot in Figure 14 corresponds to the daily yield output for both monofacial and bifacial at $45^{\circ}$ tilt angle, see Figure 13, which confirms the accuracy of the predicted values.

Figure 15 shows the simulated and experimental relative energy gain of the bifacial module compared to the monofacial one for the $25^{\circ}$ and $45^{\circ}$ degree angles respectively. The value of the relative RMS-error between the experimental and corrected simulation values is also displayed in each graph. Both graphs show that the experimental and simulated curves are very close with each other, which is also confirmed by the corresponding small value of the relative RMS-errors, which is in the same range or better than those in the literature [45], [46], [47], thus verifying the accuracy of the bifacial model simulation. The bifacial module installed at $45^{\circ}$ degrees show slightly higher energy gain compared to the $25^{\circ}$ degrees installation as expected due to increased irradiance on the back surface as a result of the higher tilt angle. 

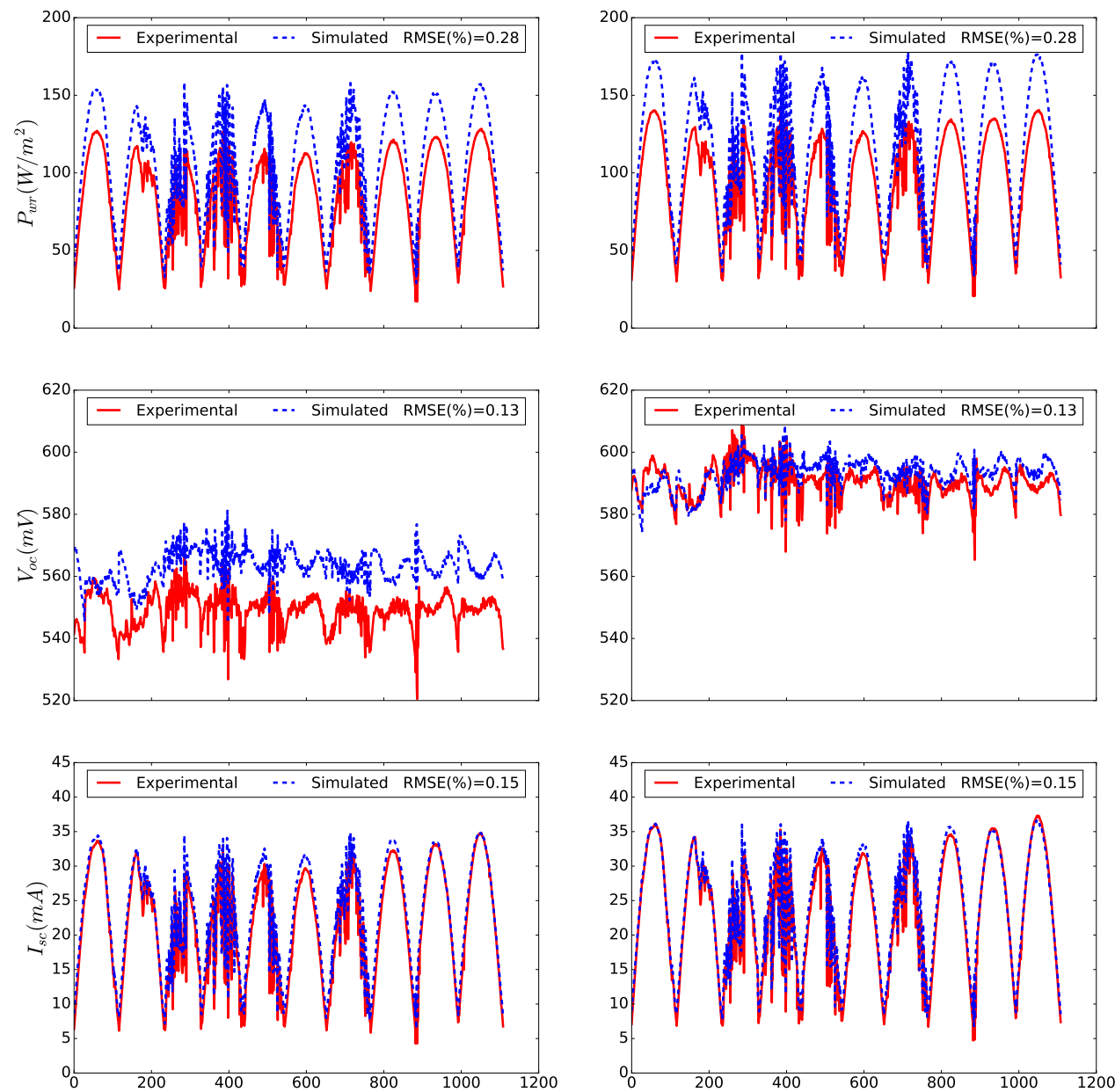

Figure 9: Comparison of measured(red solid line) and simulated(blue dashed line) results at $25^{\circ}$ : Monofacial(left), Bifacial(right), with corresponding relative RMS-errors.

Table 9: Absolute and relative differences of simulated and corrected simulated daily yield output with respect to measurements

\begin{tabular}{|l|c|c||c|c|}
\hline & \multicolumn{2}{|c||}{ Simulated } & \multicolumn{2}{c|}{ Corrected } \\
\hline & Abs-Diff $(k w h / k w p)$ & Rel-Diff(\%) & Abs-Diff $(k w h / k w p)$ & Rel-Diff(\%) \\
\hline Monofacial, $25^{\circ}$ & 2.67 & 26.05 & 1.022 & 9.96 \\
\hline Monofacial, $45^{\circ}$ & 1.74 & 14.86 & 0.076 & 0.65 \\
\hline Bifacial, $25^{\circ}$ & 2.78 & 24.43 & 0.733 & 6.43 \\
\hline Bifacial, $45^{\circ}$ & 2.03 & 15.42 & 0.101 & 0.76 \\
\hline
\end{tabular}

It is worth noting, that in the case of the $25^{\circ}$ degrees installation, for a specific period (March 29th till April 4th), the simulated bifacial power gain underestimates the corresponding experimental one quite significantly. This is related to the sandstorm mentioned earlier and can be attributed to the increased diffused component of the solar radiation where light is scattered by the airborne dust particles as already mentioned in our previous work [23]. During such conditions, the portion of light which is received from the back surface of the bifacial module is relatively increased resulting to improved conversion compared 

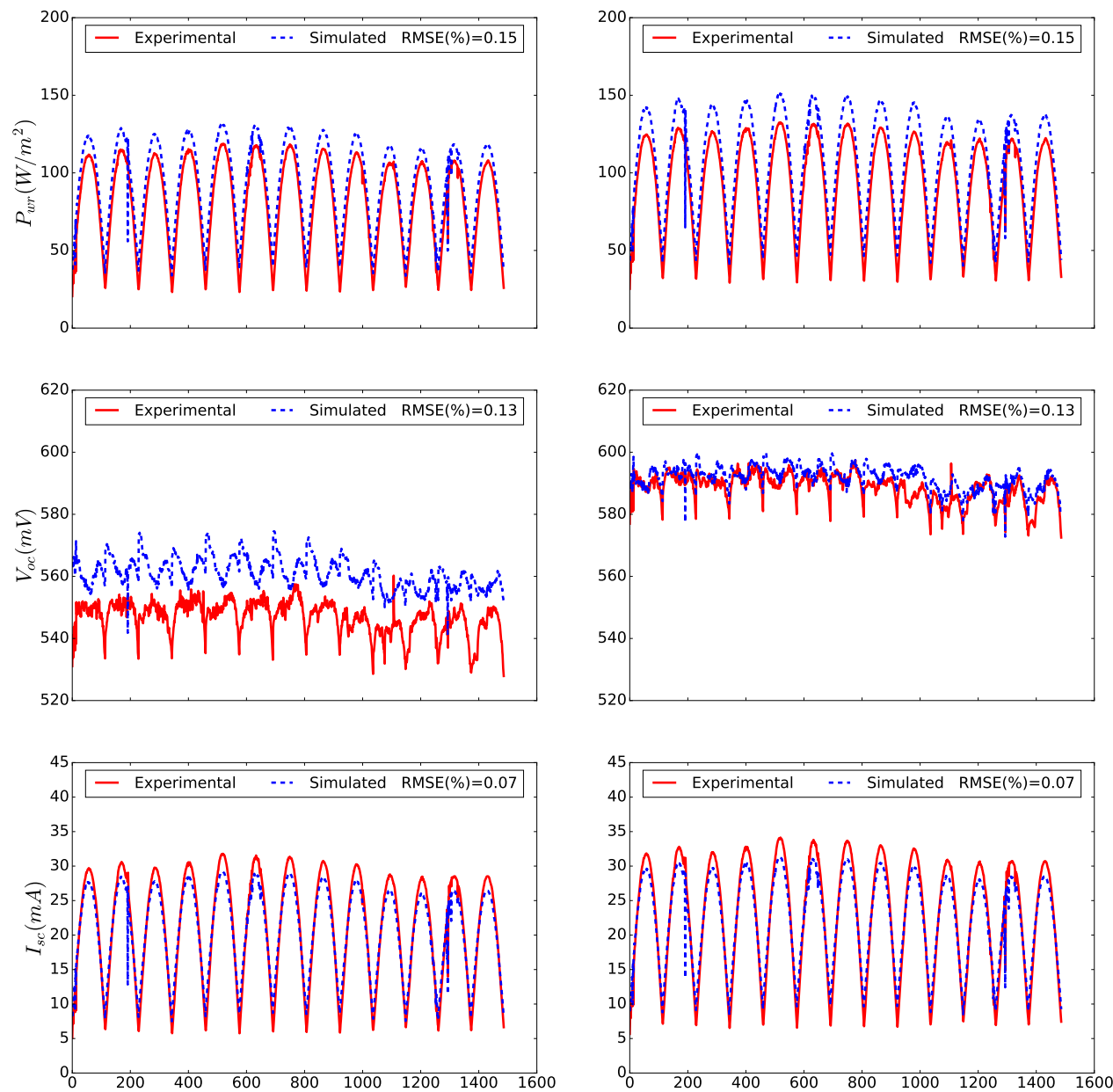

Figure 10: Comparison of measured(red solid line) and simulated(blue dashed line) results at $45^{\circ}$ : Monofacial(left), Bifacial(right), with corresponding relative RMS-errors.

to the monofacial one. This fact is clearly evident from the experimental curve, where the daily bifacial gain is maximized at the peak of the event (March 30th) and it's gradually reduced during the next days to values close to the ones before the dust storm since the dust particles are either settled on the ground or blown away by the wind. The fact that this change is not so profound in the simulations could be possibly attributed to the back irradiance sensor, where its sensitivity might not be sufficient due to the low light level measurement range involved or would require a more precise calibration for spectral mismatches for such conditions [48], thus in this particular situation it probably underestimates the amount of light on the back module surface. To further investigate the effects of the dust storm, a comparative plot of the global sunlight spectra at noon $(12: 30 \mathrm{pm})$ for two different dates is illustrated on Figure 17. The AM1.5 Global is also added as a reference. The spectrum on March 28th (black curve) is received on a clear day before the sandstorm, while the one on April 4th (blue curve) is after the event, where the relatively high concentration of airborne dust particles has changed the color of the sky from blue to a yellowish tint as also shown on the sky camera snapshot of Figure 16. The comparison of both spectra show that after the sandstorm event, the intensity of the solar spectrum has been significantly reduced, especially at UV and visible wavelengths, while at near IR region (beyond $800 \mathrm{~nm}$ ) it remains almost unchanged. This spectrum change also affects PV module performance as already mentioned. 

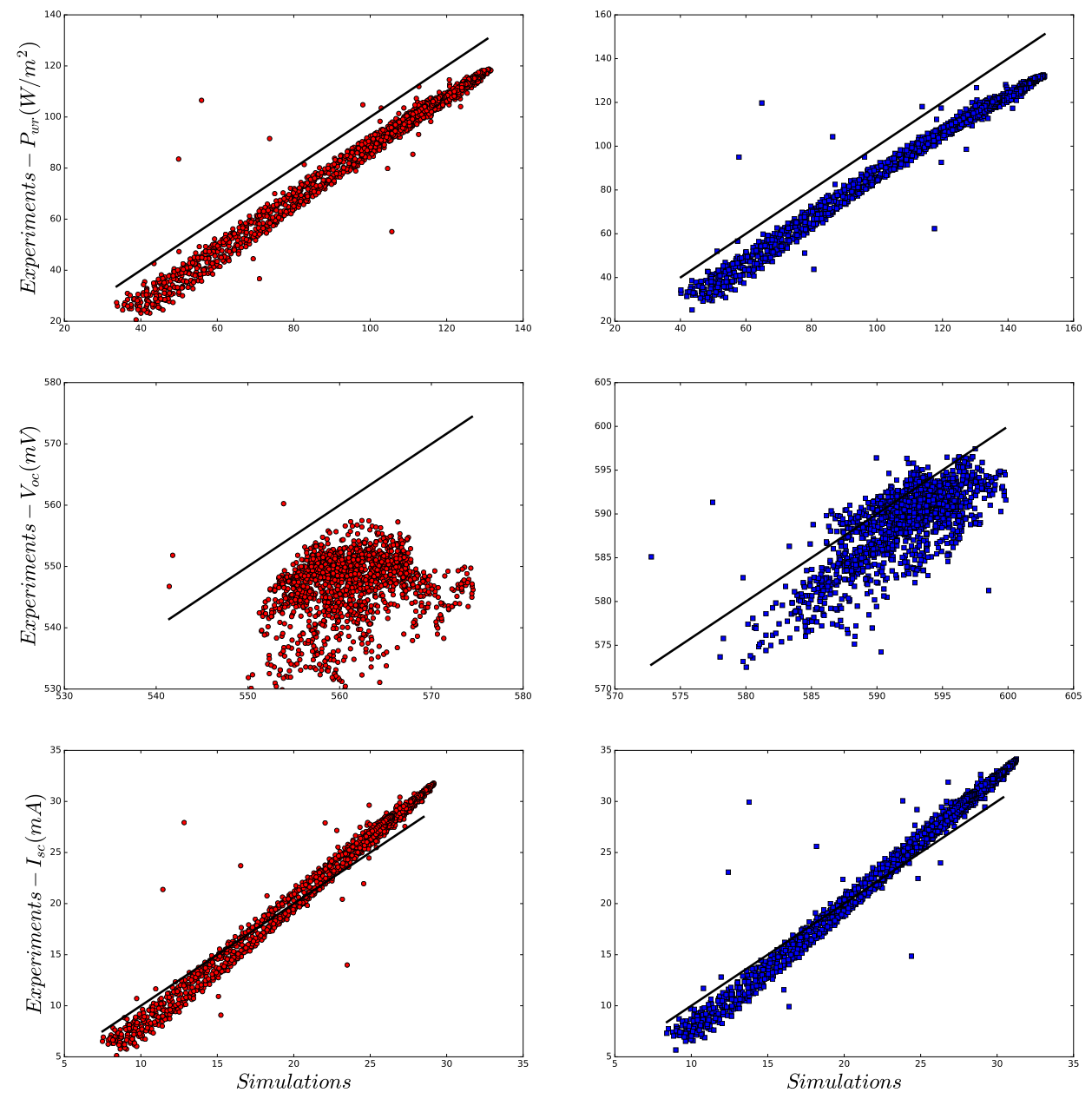

Figure 11: Parity plot between simulation results and experimental values at $45^{\circ}$ : Monofacial(left), Bifacial(right). The parity line (black solid) is also added as a reference.

\section{Discussion}

The previous section describes the application of our developed model, which is customized to simulate bifacial structures, and validated with experimental data. The custom model is based on the solution of the $2 \mathrm{D}$ solar cell device transport equations. The solver is based on the finite element method and uses mesh adaptivity to capture the Dirac like behaviour of the incoming light on the top surface and the steep gradients of the solution around the back contact of the complicated PV structure. Further, it implements an adaptive algorithm to choose the voltage step in the calculation of an IV-curve. A novel approach was presented to calculate the module temperature by taking a linear combination of various temperature models through linear square fitting. The customized model also incorporates locally measured solar spectra for precise calculation of actual PV module performance. This is an important aspect, since it has been already demonstrated in [49] that both shape and power of solar spectrum have an important weight on PV module performance. The results demonstrate that the bifacial structure has a significant energy yield advantage compared to the monofacial one. There is a $10 \%$ energy gain of the bifacial module over the monofacial one for the $25^{\circ}$ angle while the corresponding gain for the $45^{\circ}$ tilt angle is about $15 \%$. Although our assessment was based on a specific experimental setup, other aspects could be investigated such as the ground albedo using materials with higher reflectivity, and increased 

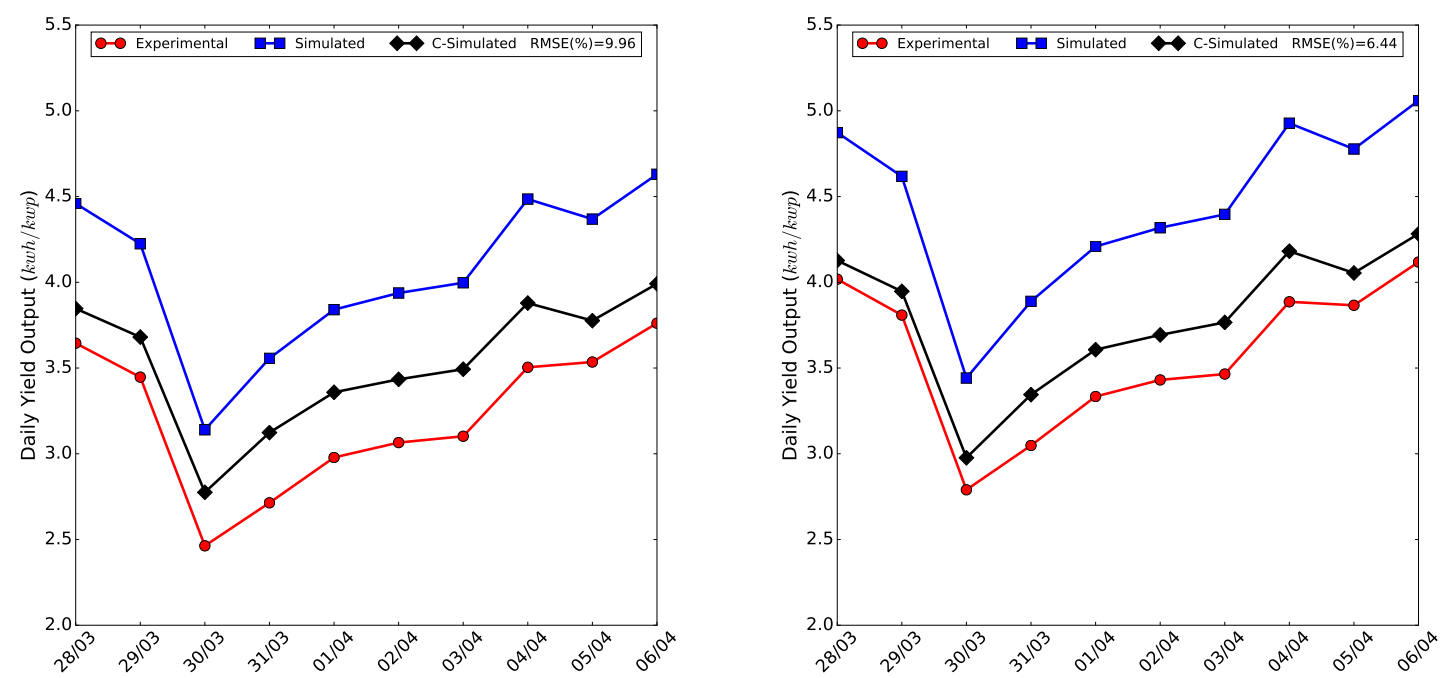

Figure 12: Daily yield output $(k w h / k w p)$ for $25^{\circ}$ tilt angle: Monofacial(left), Bifacial(right), along with the relative RMS-errors.
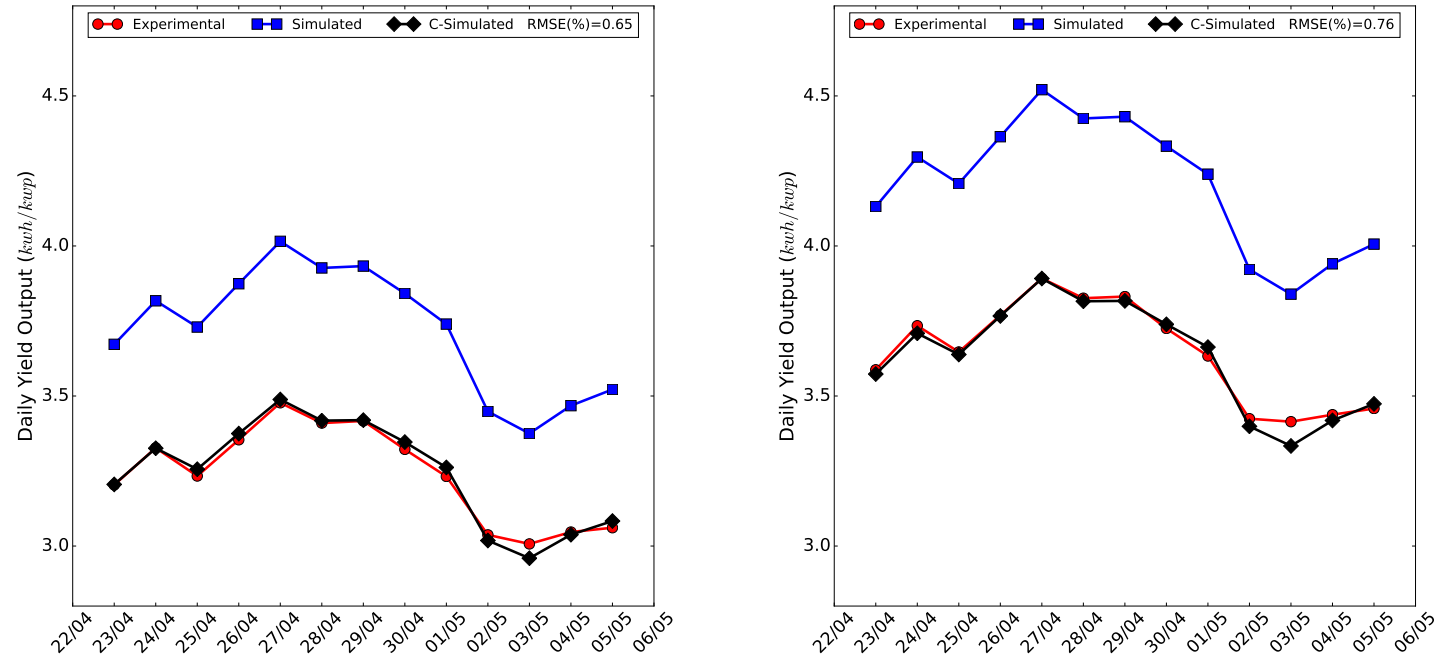

Figure 13: Daily yield output $(k w h / k w p)$ for $45^{\circ}$ tilt angle: Monofacial(left), Bifacial(right), along with the relative RMS-errors.

bifacial module elevation to increase incoming light from the back surface. Furthermore, ground material may not have uniform reflectivity for all light wavelengths absorbed by the module which, in turn, can have significant impact on the bifacial module performance [50]. Such effects were not currently taken into account into our simulations, however they can be easily added into the model by using detailed reflectance curves of the ground material.

In addition, using proper statistical analysis and advanced prediction algorithms on long term weather data like temperature and solar spectrum, this customized model may predict with high accuracy bifacial and monofacial module energy yield. This is important for the Middle East region, where dust storms significantly affect solar radiation by scattering light and alter sunlight spectrum. Such effects can provide a specific advantage for the bifacial devices due to increased diffuse light entering the back surface and should be investigated in detail. 

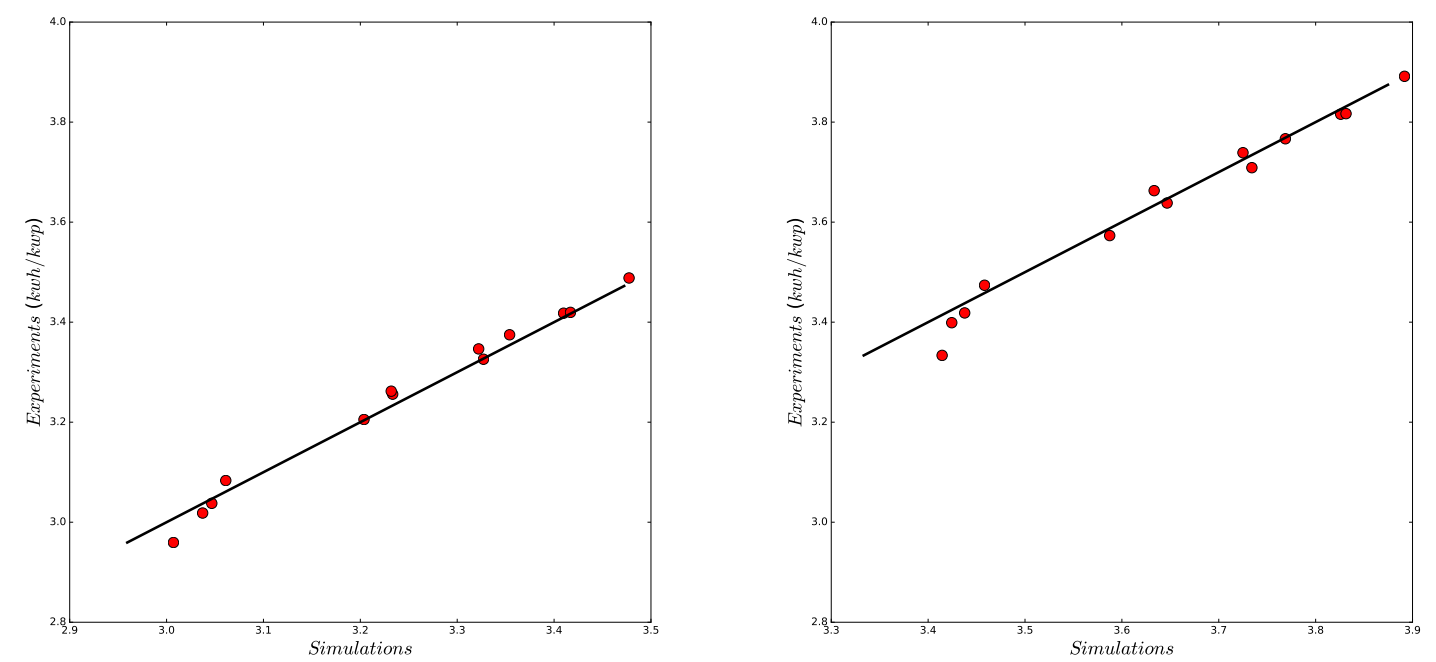

Figure 14: Parity graph of the daily yield output $(k w h / k w p)$ for $45^{\circ}$ tilt angle: Monofacial(left), Bifacial(right). The parity line (black solid) is also added as a reference.
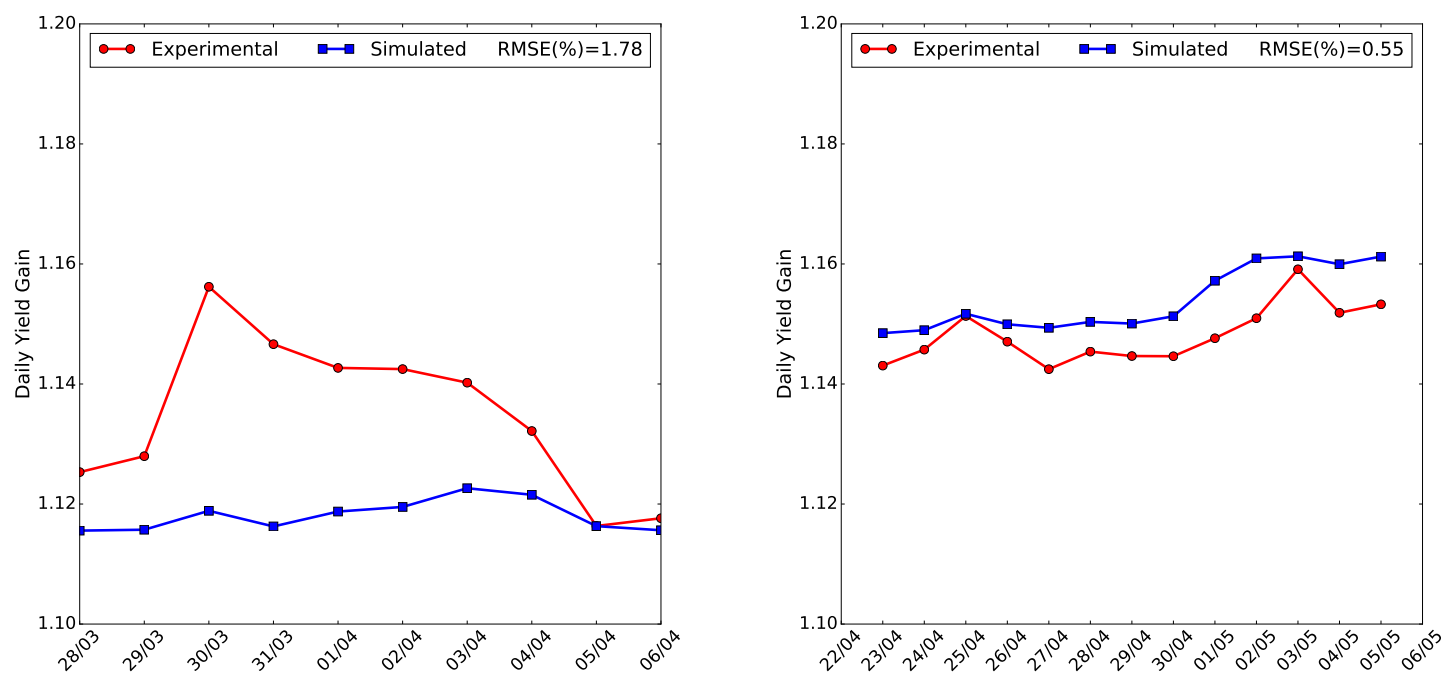

Figure 15: Daily energy yield gain : Bifacial / Monofacial for $25^{\circ}$ (left), $45^{\circ}$ (right), along with the relative RMS-errors.

\section{Conclusions}

We have presented a series of comparisons between experimental data obtained from a set of one monofacial and a bifacial PV module installed nearby the western coast of Saudi Arabia and the results of a customized solar cell device simulator developed to take into account spectral and temperature effects. The simulated results predict very well the daily yield output for both devices. The bifacial device shows a gain of $10 \%$ and $15 \%$ for $25^{\circ}$ and $45^{\circ}$ tilt angle, respectively, when compared to the monofacial one. Our results further suggest that for PV installations in the Middle East region where sandstorms are frequent, it would be beneficial using bifacial devices over monofacial ones since they can absorb more of the diffused sunlight which is in abundance when such phenomena occur. 

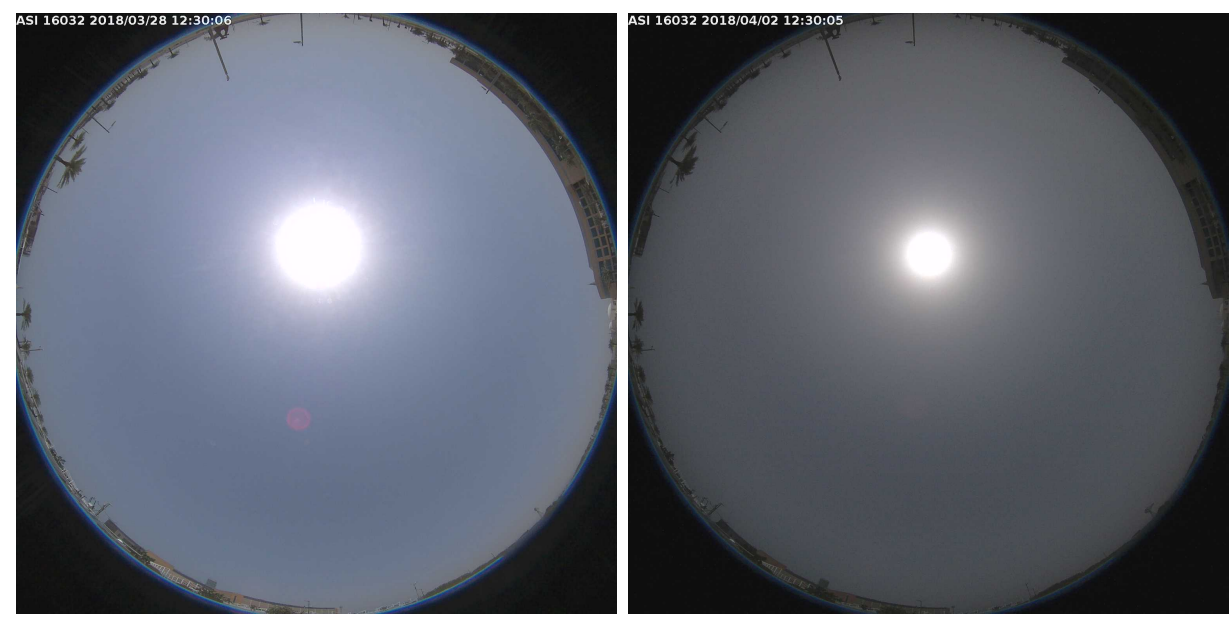

Figure 16: Sky camera snapshot at 12 : 30 local time : 2018/03/28(left), 2018/04/02(right)

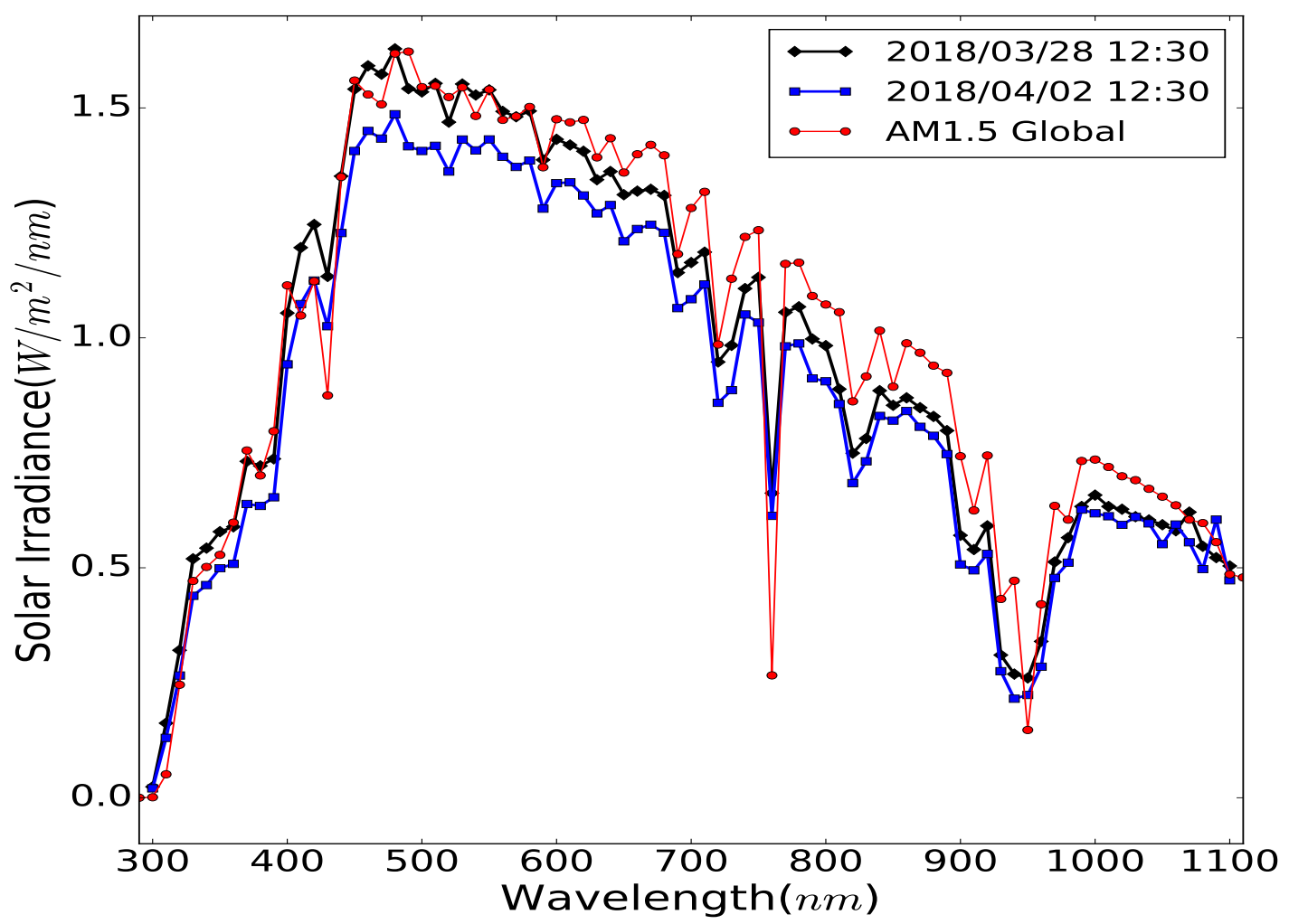

Figure 17: Spectrum comparison measured for 2 different dates at noon (12:30 pm local time) and the Global AM15 reference.

\section{Acknowledgments}

The authors acknowledge the support of the Supercomputing Laboratory at King Abdullah University of Science \& Technology (KAUST) in Thuwal, Saudi Arabia; the KAUST Economic development for their technical support and Saudi Aramco R\&D Center - Carbon Management Division for their financial 
support in developing this work. This work was partially supported by grant $R G C \# 3893$ from Saudi Aramco.

\section{References}

[1] S. Wanga, O. Wilkieb, J. Lam, R. Steeman, W. Zhang, K-S Khoo, S-C Siong, and H. Rostan. Bifacial photovoltaic systems energy yield modelling. Energy Procedia, 77:428 - 433, 2015.

[2] Y. Chieng and M.A. Green. Computer Simulation of Enhanced Output from Bifacial Photovoltaic Modules. Progress in Photovoltaics: Research \& Applications, 1:293-299, 1993.

[3] T. Joge, Y. Eguchi, Y. Imazu, I. Araki, T. Uematsu, and K. Matsukuma. Applications and field tests of bifacial solar modules. In Proc. 29th IEEE PV Specialists Conference, pages 1549-1552, 2002.

[4] J. Libal, D. Berrian, and R. Kopecek. Overview: energy yield simulations and calculation of LCOE for bifacial PV systems. In bifi PV Workshop, Konstanz, Germany, 2017.

[5] https://www.pv-tech.org/news/acwa-power-wins-saudi-300mw-solar-project 2018.

[6] T. Warabisako, K. Matsukuma, S. Kokunai, Y. Kida, T. Uematsu, and H. Yagi. Bifacial multicrystalline Silicon solar cells. In Proc. 23rd IEEE PV Specialists Conference, pages 248-251, 1993.

[7] A. Moehlecke, I. Zanesco, and A. Luque. Practical high efficiency bifacial solar cells. In Proc. 24th IEEE PV Specialists Conference, pages 1663-1666, 1994.

[8] SolarWorld. SunModule, BiSun, http://www.solarworld.de.

[9] Trinasolar. DUOMAXtwin, http://www.trinasolar.com.

[10] Sunpreme. GxB series, http://sunpreme.com/gxb-series-2.

[11] NEO Solar Power Corporation (NSP). BiFi Series, http://www.nsp.com/s/2/product-c73729/BiFiBifacial-Cell.html.

[12] ITRPV. International Technology Roadmap for Photovoltaic Results 2016. Technical report, ITRPV, 2017.

[13] A. W. Blakers, A. Wang, A. M. Milne, J. Zhao, and M. A. Green. $22.8 \%$ efficient silicon solar cell. Applied Physics Letters, 55(13):1363, 1989.

[14] I. Romijn, I. Cesar, M. Koppes, E. Kossen, and A. Weeber. Pasha: A new industrial process technology enabling high efficiencies on thin and large mc-Si wafers. In IEEE Photovoltaic Specialists Conference, 2008.

[15] Yingli Solar. Bifacial modules, http://www.yinglisolar.com/en/products/solar-modules/.

[16] M. Taguchi, A. Yano, S. Tohoda, K. Matsuyama, Y. Nakamura, T. Nishiwaki, K. Fujita, and E. Maruyama. 24.7 \% Record Efficiency HIT Solar Cell on Thin Silicon Wafer. IEEE Journal of Photovoltaics, 4(1):96-99, 2014.

[17] M. Burger. Heterojunction technologies, https://www.meyerburger.com/gr/en/technologies/photovoltaics/highefficiency-technologies/heterojunction/.

[18] X. Sun, M. R. Khan, C. Deline, and M.A. Alam. Optimization and performance of bifacial solar modules: A global perspective. Applied Energy, 212:1601-1610, 2018.

[19] PVSyst. Photovoltaic software, http://www.pvsyst.com/en/.

[20] Valentin Software. Photovoltaic software, https://www.valentin-software.com/en/products/.

[21] Laplace Systems. SolarPro, http://www.laplacesolar.com/photovoltaic-products/solar-pro-pvsimulation-design/. 
[22] Archeliospro. PV simulation software, http://www.archelios.com/pvsoftware.php.

[23] Th. Katsaounis, K. Kotsovos, I. Gereige, A. Al-Saggaf, and A. Tzavaras. 2D simulation and performance evaluation of bifacial rear local contact c-Si solar cells under variable illumination conditions. Solar Energy, 158:34-41, 2017.

[24] K. Kotsovos and K. Misiakos. Three-dimensional simulation of carrier transport effects in the base of rear point contact silicon solar cells. Journal of Applied Physics, 89(4):2491-2496, 2001.

[25] F. Hecht. New development in FreeFem++. J. Numer. Math, 20:251-265, 2012.

[26] IMT solar. https://www.imt-solar.com/.

[27] PVPMC. Modeling collaborative workshop, IEA-PVPS T13-06, 2017.

[28] EKO Instruments. https://eko-eu.com/.

[29] Campbell Scientific. https://www.campbellsci.com/cr1000.

[30] PV-Lighthouse. https://www.pvlighthouse.com.au.

[31] M. Zanuccoli, R. DeRose, P. Magnone, E. Sangiorgi, and C. Fiegna. Performance Analysis of Rear Point Contact Solar Cells by Three-Dimensional Numerical Simulation. IEEE Transactions on Electron Devices, 59(5):1311-1319, 2012.

[32] R. Horbelt, G. Micard, P. Keller, R. Job, G. Hahn, and B. Terheiden. Surface recombination velocity of local Al-contacts of PERC solar cells determined from LBIC measurements and 2D simulation. Energy Procedia, 92:82-87, 2016.

[33] J. A. Duffie and W. A. Beckman. Solar Engineering of Thermal Processes. Wiley, 2006.

[34] J. M. Servant. Calculation of the cell temperature for photovoltaic modules from climatic data. In Proceedings of the 9th biennial congress of ISES-Intersol 85, 1985.

[35] R. Chenni, M. Makhlouf, T. Kerbache, and A. Bouzid. A detailed modeling method for photovoltaic cells. Energy, 32:1724-1730, 2007.

[36] F. Lasnier and T. G. Ang. Photovoltaic engineering handbook. Adam Hilger, 1990.

[37] D. L. King, W. E. Boyson, and J. A. Kratochvill. Photovoltaic array performance model, 2004.

[38] EU-IET. Photovoltaic geographical information system (http://re.jrc.ec.europa.eu/pvgis/).

[39] S. Krauter and A. Preiss. Comparison of module temperature measurement methods. In 34th IEEE Photovoltaic Specialists Conference (PVSC), 2009.

[40] M. A. Green. Self-consistent optical parameters of intrinsic silicon at $300 \mathrm{k}$ including temperature coefficients. Solar Energy Materials \& Solar Cells, 92:1305-1310, 2008.

[41] P. Singh and N.M. Ravindra. Temperature dependence of solar cell performance - an analysis. Solar Energy Materials \&3 Solar Cells, 101:36-45, 2012.

[42] D.B.M. Klaassen. A unified mobility model for device simulation-ii. temperature dependence of carrier mobility and lifetime. Solid State Electronics, 35(7):961-967, 1992.

[43] K.C. Fong, K.R.McIntosh, and A.W. Blakers. Accurate series resistance measurement of solar cells. Prog. Photovolt: Res. Appl., 21:490-499, 2013.

[44] M. Chegaar, A. Hamzaoui, A. Namoda, P. Petit, M. Aillerie, and A. Herguth. Effect of illumination intensity on solar cells parameters. Energy Procedia, 36:722-729, 2013.

[45] M. Klenk, H. Nussbaumer, M. Morf, T. Baumann, F. Baumgartner, D. Berrian, J. Libal, G. Janssen, A. Binani, and T. Burgers. BIFOROT : Bifacial Outdoor Rotor Tester. In bifi PV Workshop, Denver, USA, 2018. 
[46] D. Buss, E. Herzog, C. Scholz, R. Zimmermann, and B. Eisenhawer. Outdoor characterization of bifacial modules at Hanwha Q cells. In bifi PV Workshop, Denver, USA, 2018.

[47] D. Berrian, J. Libal, and S. Glunz. MoBiDiG : simulations and LCOE . In bifi PV Workshop, Konstanz, Germany, 2017.

[48] H. Mullejans, A. Ioannides, R. Kenny, W. Zaaiman, H.A. Ossenbrink, and E. Dunlop. Spectral mismatch in calibration of photovoltaic reference devices by global sunlight method. Meas. Sci. Technol, 16:1250-1254, 2005.

[49] Aitor Marzo, Pablo Ferrada, Felipe Beiza, Pierre Besson, Joaquín Alonso-Montesinos, Jesús Ballestrín, Roberto Roman, Carlos Portillo, Rodrigo Escobar, and Edward Fuentealba. Standard or local solar spectrum? implications for solar technologies studies in the atacama desert. Renewable Energy, 127:871-882, 2018.

[50] T. Russell, R. Saive, A. Augusto, S. Bowden, and H. Atwater. The influence of spectral albedo on bifacial solar cells: A theoretical and experimental study. IEEE Journal of Photovoltaics, 7(6):1611$1618,2017$. 